\title{
Is regional redistribution harmful for growth? An empirical analysis on the Spanish Autonomous Communities. 2002-2016
}

\author{
Joan Rosselló Villalonga (Universitat Illes Balears) \\ Guillem López Casasnovas (Universitat Pompeu Fabra)
}

\begin{abstract}
In this paper we estimate the relationship between the growth rate of Spanish regions' GDP and the level of regional redistribution. We will do so considering the period 2002-2016 using a panel of 17 Spanish regions. Our estimates suggest that regional redistribution has a negative impact on regional GDP growth rates, regardless of whether the region is recipient or donor of fiscal transfers. This suggests that territorial redistribution as it comes out from the central transfers is harmful for growth. A policy implication of our results is that donor regions do find in the Spanish context a solid argument for secession, especially in a framework where Regional Governments, or regional interests, are not well represented in the Spanish institutions in order to modify the present state of affairs
\end{abstract}

Key words: interregional transfers, growth, secession, internal exit.

JEL:

\section{Introduction}

There is a wide array of arguments in any demand for secession, or internal exit of a minority group from a given coalition: cultural differences, language, political interests, and last but not least, economics. To the best of our knowledge we are not aware of any process of secession that is guided for economic interests exclusively. Most processes are leaded by a majority of a population in a territory (a minority may be in nation-wide terms) that shares common cultural and historical links: Economic mistreatment is just another argument to reinforce the other ones. Catalonia, Quebec or the situation in Flanders, even the Brexit, are good examples.

The recent events occurred in Catalonia in 2017 in which a large share of the population demanded, and still do, a revision of the status of this region in Spain has motivated an enormous increase of the contributions in the literature analyzing this process. However, only a few of them estimate, from a fiscal and economic perspective, the costs and benefits in case that secession occurred (Ganzia et al 2017, Borrell 2015, Bosch 2013, Cuadras et al 2011, Rodriguez 2012, Castells 2014, Cuadras et al 2017, etc.). One of the arguments of those in favour of internal exit is that in a country without the possibility of secession, or without a National Parliament in which regions are effectively represented so that their opinions are considered in those matters that affect their interests, the redistribution of public resources between rich and poor regions is excessive, this being harmful for their economic growth. Opponents to secession argue that the benefits of belonging to the union are much larger than the benefits of 
secession, basically because they assume that the seceded region would be excluded from the European Union

It is important to stress that the issue of secession is not a new topic in the literature ${ }^{1}$, since there is a large number of contributions that deal with the issue of interregional redistribution. Just to mention some of them, Buchanan and Faith (1987) study how the option of secession limits the amount of fiscal surplus that a ruling majority can obtain from a minority, which is equivalent to saying that the possibility of secession limits the amount of redistribution; they also shed some light on the size and number of coalitions. Bolton and Roland (1997), following a political economy approach, analyze the limits of taxation and redistribution in a model in which there are income differences within regions and regional differences on the preferences for redistribution under the threat of secession; they state that integration constraints the choice of public policy of the regions. See also Dagan and Volij (1997) and Ellingsen (1997), both of them dealing with theoretical models in which they analyze the possibilities of fiscal policies among countries in a framework in which secession is a plausible outcome.

In this paper we want to estimate, from an empirical perspective, the implications of regional redistribution in a decentralised union in which the possibility of secession is not plausible, for political reasons. Our estimates are based on a theoretical model of endogenous growth by Rossello (2003) in which the author proves that, under certain conditions, regional redistributions is harmful even for the recipients of fiscal transfers. The argument is as follows. On the one hand, the model indicates that an increase in regional redistribution implies an increase of transfers from the rich to the poor region. These transfers are expected to increase welfare in the recipient region in the short run. On the other hand, higher redistribution has a negative effect on the growth of rate of the rich region's GDP. Given that the model is an endogenous growth model in an open economy and that the growth rate of the economy depends on the marginal productivity of capital in the rich region, the negative effect of redistribution on the growth rate of the rich regions translates into a negative effect on aggregate GDP. Therefore, under higher redistribution the poor region will receive larger resources at time $t=0$; nevertheless, these resources grow at a lower rate. In a temporal framework with $t \rightarrow \infty$, the negative effect dominates the positive one. However, to what concerns the rich region, the effect of redistribution, which is aimed at reallocation factors of production among regions, is negative both in the short and long run, because redistribution means that a share of taxes collected in the rich region does not return in the form of public productive investment ${ }^{2}$.

Therefore, our goal is to estimate the relationship between the growth rate of the Spanish regions' GDP and the level of regional redistribution. We will do so considering the period 2002-2016 using a panel of 17 Spanish regions. In particular, in our estimations we will differentiate between tax and expenditure effects and redistribution effects (the share of taxes that do not return, or return in excess, to the regional economy where they are collected.

If a negative relationship was not found, then any secessionist argument based on the idea that redistribution is harmless for growth might be discarded. On the contrary, if a negative relationship was found, this would provide arguments to secessionists to fix some limits to regional redistribution or even

\footnotetext{
${ }^{1}$ As it is the issue of whether reducing inequality enforces economic growth.

${ }^{2}$ This effect is exacerbated if resources are used to increase labor. That change in the labor to capital ratio delays innovation and create a dependency path of the central transfer to finance operating salaries and crowding out capital investment.
} 
to secede from the federation, if this possibility existed. In this last case, poorer regions should also be interested in limiting redistribution were they considering the long run instead of short run effects.

There are several contributions (using Spanish data) that analyze the impact of public investment on regional growth and its efficiency. In particular, De la Fuente (2008) analyzes the impact of public investment on regional convergence in the Spanish Autonomous Communities for the period 1965-2004. They estimate a production function in which public and private capital play a significant role and they estimate the impact of public investment on regional growth and regional convergence. Two results are of interest. On the one hand, he shows that public investment has had a significant impact on regional converge during the period of analysis. However, and more relevant to our research, the author shows that there exist a clear trade-off between redistribution and efficiency of public investment. De la Fuente (2004) analyzes the optimality of public investment policy in Spain, where he concludes that public investment has been too redistributive in this country. Hence, he concludes that "average welfare could be increased by raising the weight given to efficiency considerations in the regional allocation of infrastructure investment. In practice, this would involve investing a lot more in some of the richest regions and considerably less in some of the poorest ones." However, in none of the articles De la Fuente does not deal with regional redistribution, which is what we try to do in our paper.

We must also refer to the contribution by Petchy (2016) where he analyzes what is the link between equalization, the spatial allocation of mobile factors of production, and economic efficiency. His main findings are that the inter-state transfer that occurs with equalization is inconsistent with an efficient spatial allocation of mobile factors of production within a regional economy.

In the next section we present the main characteristics of the model we want to estimate. In section 3 we present the results of our estimations and we conclude in section 4.

\section{The model}

Our estimates are based on the theoretical model contained in Rossello (2003), where the author analyses the effects of redistribution on regional economic growth, both for the recipient and the donor regions.

In his model, in a framework with free circulation of capital across regions, there is a central administration that collects a tax on output, which is the same in all regions, and redistributes these revenues across regions by investing in public infrastructures. The model analyzes to which extent regional redistribution is harmful for growth, both for the rich and the poor regions.

The model is as follows.

\section{II.1 Consumers}

The problem for the infinite-lived agent in region $i$ is to maximize the overall utility:

$$
\begin{gathered}
\text { Max Ui } \int_{0}^{\infty} e^{-\rho t} \frac{c_{t i}^{1-\theta}-1}{1-\theta} L_{t i},(1) \\
\text { s.t } a_{t i}=r_{t} a_{t i}+w_{t i}-c_{t i} \text {, (2) } \\
\quad a(0)_{i} \geq 0, i=R, P \text {. (3) }
\end{gathered}
$$


Where $c_{t i}$ is consumption per capita and $\rho$ is the rate of time preference. He defines $1 / \theta$ as the constant inter temporal elasticity of substitution; $r_{t i}$ is the market interest rate and $w_{t i}$ represents his wage, both are taken as given by households. $L_{t i}$ is the family size, which evolves at a zero growth rate.

Households are assumed to be immobile and they supply labor inelasticaly. In addition to that, they assume that all agents have the same preferences, meaning that $\rho$ and $\theta$ are the same for any representative agent.

Finally, agents offer their capital $\left(a_{t i}\right)$ to domestic firms and firms in the other region and their receive $r_{t i}$

\section{II.2 Firms}

In Rosselló (2003) firms maximize after tax profits:

$$
\operatorname{Max} \pi_{t i}=(1-\tau) Y_{t i}-r_{t i} K_{t i}-w_{t i} L_{t i},(4)
$$

where

$$
Y_{t i}=A_{i} K_{t i}^{\alpha}\left(L_{t i} G_{t i}\right)^{1-\alpha} \text { (5) }
$$

$L_{t i}$ and $K_{t i}$ denote the amounts of labor and capital input, respectively. $G_{t i}$ represents the public services available for each producer in region $i . A_{i}$ reflect region specific characteristics that affect production and it is exogenous to the model (for $i=R$ and $P$, denoting rich and poor regions respectively). They assume that $A_{R}>A_{P}$ which is sufficient for $Y_{t R}>Y_{t p}$ to hold before redistribution. $\tau$ is a tax rate per unit of output.

\section{II.3 Government}

There is a Central Government (CG) that provides local public services $\left(G_{t i}\right)$ across regions that are used by firms in the production process. No regional externalities are considered regarding $G_{t i}$. The CG fixes a proportional tax on output at a rate $\tau$ such that provides $R_{t}$ revenues, such that the balanced budget constraint follows:

$$
G_{t}=\left(G_{t R}+G Y_{t P}\right)=R_{t}=\tau\left(Y_{t R}+Y_{t P}\right),(6)
$$

and

$$
G_{t R}=\tau(1-\beta) Y_{t R}, G_{t P}=\tau\left[Y_{t P}+\beta Y_{t R}\right](7)
$$

$B$ is the share of the tax revenue collected in the richer region that is devoted to provide additional public productive services to the poorer regions.

\section{II.4 Main results}

There are two main results that are to be tested in this article. On the one hand, Rossello (2003) finds that regional redistribution has a negative effect on economic growth in both regions. On the other, he finds the effects of regional redistribution on the households' welfare in both regions.

\section{II.4.1 Regional redistribution and growth}

By solving the model, the author finds that all regions grow at the same constant rates and that, as expected, all variables grow at the same rate. In particular, they find 


$$
\gamma_{C}=\gamma_{K}=\gamma_{G}=\gamma_{Y}=\frac{1}{\theta}\left[A_{R}^{\frac{1}{\alpha}}(1-\tau) \alpha[(1-\beta) \tau]^{\frac{1-\alpha}{\alpha}}-\rho\right](8)
$$

His results derive from the fact that regional redistribution reallocates public resources from the productive region to the less-productive one, compensating for differences in productivities. Therefore, the CG induces a reallocation of factors of production because $G_{t i}$ affects the marginal product of capital in each of the regions.

Given that all regions grow at the same rates, it can be concluded that regional redistribution has a negative impact on growth regardless whether the region is rich or poor.

\section{II.4.2 Regional welfare}

The second result to be remarked is the effect of regional redistribution on household's welfare.

The maximum level of welfare attainable in any of the regions follows

$$
U_{\max i}=\frac{1}{1-\theta}\left[\frac{c(0)_{i}^{1-\alpha}}{\rho-\gamma_{c}(1-\theta)}-\frac{1}{\rho}\right], i=R, P(9)
$$

where $c(0)_{i}$ is the initial level of consumption (the one satisfying the transversality condition) in region $i$, which is also affected by $\beta$.

Graphically, consumption follows

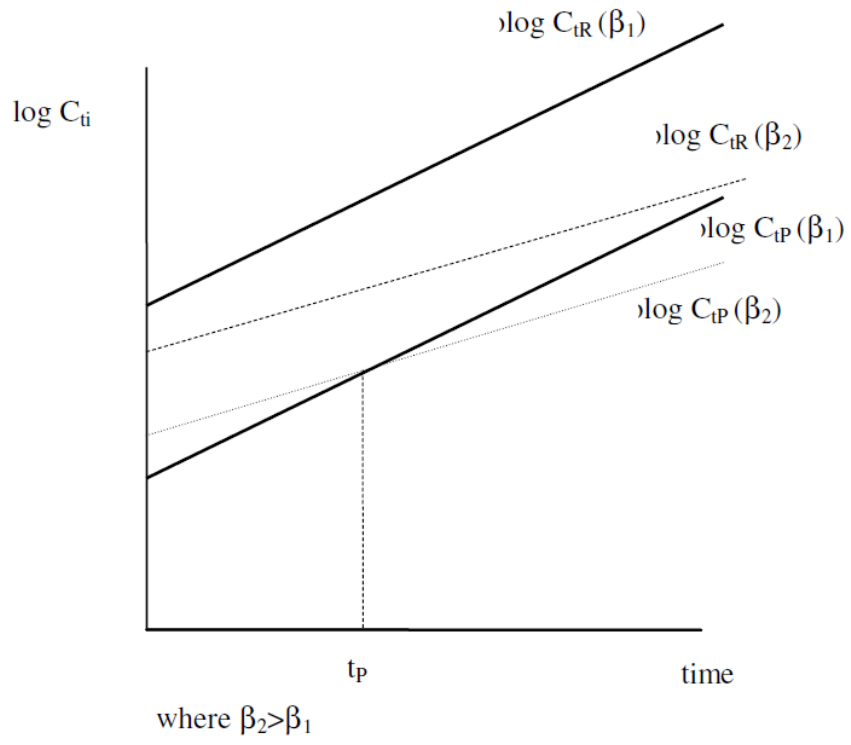

Figure(1)

To what concerns households in the rich region, the author shows that it is always the case that redistribution is harmful for welfare. This is due to the fact that redistribution causes a negative effect on the initial level of consumption as well as on its growth rate.

However, this result is not so straight forward with respect to households in the poor regions; while regional redistribution has a positive effect on their initial level of consumption, it has a negative effect on its growth rate. Therefore, from $t_{p}$ on consumption in the poor region is below the level that would be obtained with a lower level of redistribution. All in all, regional redistribution has a negative effect on 
welfare of households in region $P$ at least for $\theta \geq 1$ and $\beta \geq \alpha / 1-\alpha$, although there are other combinations of parameters for which the result might hold.

According to these results, in order to understand the effects of regional redistribution on welfare, it is crucial that we analyze whether there exists a negative relationship between this variable and consumption growth rates.

\section{The equation to be tested}

The equation to be estimated (once the terms have been reordered) for a panel of 17 regions for the period 2001-2016 is

$$
\gamma_{C t i}=\text { constant }+\delta \text { Tax }_{\text {Rate }} \text { ti }_{i}+\varphi \text { Redistribution }_{t i}+\mu \text { Other }_{t i}+\varepsilon_{t i}(10)
$$

We estimate this equation based on data on Regional Domestic Product in per capita terms. It is important to stress that we will only consider regional redistribution through the central finance of regional governments, and we will not consider regional redistribution through local governments themselves due to the lack of data available.

$\delta$ captures the aggregate effects of fiscal policies (the positive effect of public investment and the negative effect of tax rates on GDP).

Regional Redistribution $\left(\beta_{t R}\right)$ follows (we only refer to the rich region because all revenues from that region will be transferred to the poor region)

$$
\text { Redistribution }=1-\beta_{t R}=\frac{G_{t R}}{\tau Y_{t R}}(11),
$$

$\tau Y_{t i}$ refers to total revenues while $G_{t i}$ to total expenditure in region $i$.

We estimate equation (10) using the fixed effects and the between group estimator. Since we are interested in exploring a long term relationship, we argue that the "between group" estimator is the right technique, because equation (10) is estimated based on the average of the variables across time; therefore, we avoid the cyclical component/behavior. However, we also try a fixed effect estimator considering year dummies to test whether the relationship also holds in the short run.

In addition to that, we run our regressions considering all regions at the same time and alternatively we split regions into two groups. On the one hand, we gather those regions which are recipients of transfers from the CG during all periods. On the other, we consider those regions which are donors during the period of analysis. We must remark that there is a few number of regions in this situation.

In Spain, the present financing agreement establishes two types of regional redistribution. On the one hand, we find horizontal transfers (Fondo de Garantía and Fondo de Suficiencia): some regions with total revenues larger than their expected spending needs transfer part of their shared and some of their own revenues to the other regions through the Central Government (CG) (horizontal transfers to Regional Governments (RG)). On the other hand, the CG transfers some resources too to some regions from its own revenues and from those obtained from central/regional shared taxes (vertical transfers). It is important to stress that we are not considering direct expenditures or direct investments by the CG to any region; only those transfers that represent additional revenues to RGs. This is due to the fact that there is no data available on fiscal flows from the whole CG expenditure to the regions for the complete period. 
It is important to remark that Rosselló (2003) only considers public investment. However, in this paper we consider total public expenditure. We make this assumption because for regional changes in GDP both current and capital public expenditure has an impact on income: public administrations are not selfsufficient and they buy or hire goods and services to the private sector too in addition to regional job creation.

Finally, in Other Variables we include some control variables that affect regional growth (basically, the \% of workers with post-compulsory education, among others)

\section{The data}

\section{IV.1 Data sources}

We use data from official sources mainly. The Spanish Statistics National Institute (INE) provides homogeneous time series for each region (Autonomous Communities).

Data on GDP is obtained from the Annual Regional Accounts, both at current prices and chain linked volumes (that is, at constant prices) for each region. Data on population levels to compute the per capita levels is from INE also.

The degree of redistribution and the tax rate is computed based on administrative data from the Ministerio de Hacienda. In particular, we use consolidated budget execution in order to compute the expenditure and revenues for each region. Data on Fondo de Suficiencia, Fondo de Garantia and Fondos de Convergencia, is also provided by the Ministerio de Hacienda

Another important factor which explains economic growth is human capital. In order to control for human capital in each region, we computed the share of the labor force with non-compulsory education, which includes upper secondary education, vocational training and higher education. Nevertheless, combining two different sources was required. On the one hand, IVIE ${ }^{3}$ provides the series until 2014. On the other hand, data since 2014 is from INE because earlier data is not available. We checked both data sources to test that there is not a structural change in the series from two different sources. We do not find any significant structural change.

\section{IV.1 The panel}

We selected the period from 2002 until 2016. Although there is data available on GDP and education of the labor force from 1995, our period of analysis is from 2002 to 2016. There is a trade off in having large time series (which allows to analyze long term relationships) and structural changes in the data. After analyzing the data we decided to select 2002 as our initial year because that year there was an important change in the financial agreements for most regions. This change allows finding more accurate data on regional redistribution.

Our dependent variable is the per capita real GDP growth rate. We use GDP at current prices and linked volumes GDP to compute the implicit deflator for each year and region. Once we get the deflator we get the per capita GDP dividing GDP at current prices by the deflator and the population.

\footnotetext{
${ }^{3}$ Fundación Bancaja and IVIE (Instituto Valenciano de Investigaciones Económicas). Capital Humano en España y su distribución provincial. Enero de 2014. Database available at: http://www.ivie.es/es/banco/caphum/series.php
} 
The variable Tax rate is computed considering total revenues in region $i$ as a percentage of regional GDP. Tax revenues considered are those included in chapters I (direct taxes), II (indirect taxes) and chapter III (fees) in regional budgets. Alternatively, we include squared tax rate in order to test for the nonlinearity of this variable.

We must remark that financing agreements between the CG and RGs in Spain establish that regions can fix some taxes and also that they receive revenues from shared taxes such as VAT, consumption taxes on specific goods, and Income Tax, mainly. However, we do not consider the whole amount of these revenues collected in each region, but just the amount that corresponds to the regions. This means that we assume that a share of regional taxes that remains under control of the $\mathrm{CG}$ is assumed to be devoted to finance common-interest expenditures (defense, international affairs, etc.). We are only interested here in the portion of those resources that are transferred to RGs.

We estimate equation (10) using the following variables (see appendix 1 for the main statistics of the data)

In equation (1) we show how the variable redistribution is included in the regression. It is important to stress that we do not introduce redistribution $(\beta)$, but $1-\beta$ instead. Therefore, if the coefficient $\varphi$ is positive, then results suggest that redistribution has a negative impact on regional growth: higher redistribution (higher $\beta$ ), implies lower (1- $\beta$ ), which implies a negative effect on regional growth. Values for (1- $\beta)$ below 1 indicate that this is a donor region, and a recipient for values above 1 .

$G_{t i}$ refers to total expenditure in region i, considering chapter I (wages), II (procurement), III (interests), IV and VII (transfers to private agents and to another administrations), and chapter VI (investment). It is also important to stress that we do not consider expenditure financed by issuing debt. Therefore, in case of primary deficit, this amount is detracted from $G_{t i}$.

Alternatively we use another variable to account for redistribution. We use the sum of all horizontal and vertical transfers to RGs, derived from the Financing Agreements for the Spanish Autonomous Communities (CC.AA). In Spain, financing agreements (2001 and 2009) establish two types of regional redistribution. As explained before, horizontal transfers do exist (Fondo de Garantía and Fondo de Suficiencia): some regions with total revenues larger than their estimated necessities transfer part of their shared and own revenues to the other regions through the CG (they are, in this sense, indirect transfers). In addition, the CG transfers financial resources to some regions from its own revenues (vertical transfers). It is important to remark that we are not considering direct expenditures or direct investments by the CG to any region, but only those transfers that represent additional revenues to RGs, since there is no data available on total fiscal flows from the CG to the RGs for the whole period. 
Figure 1. Redistribution across regions (AACC)

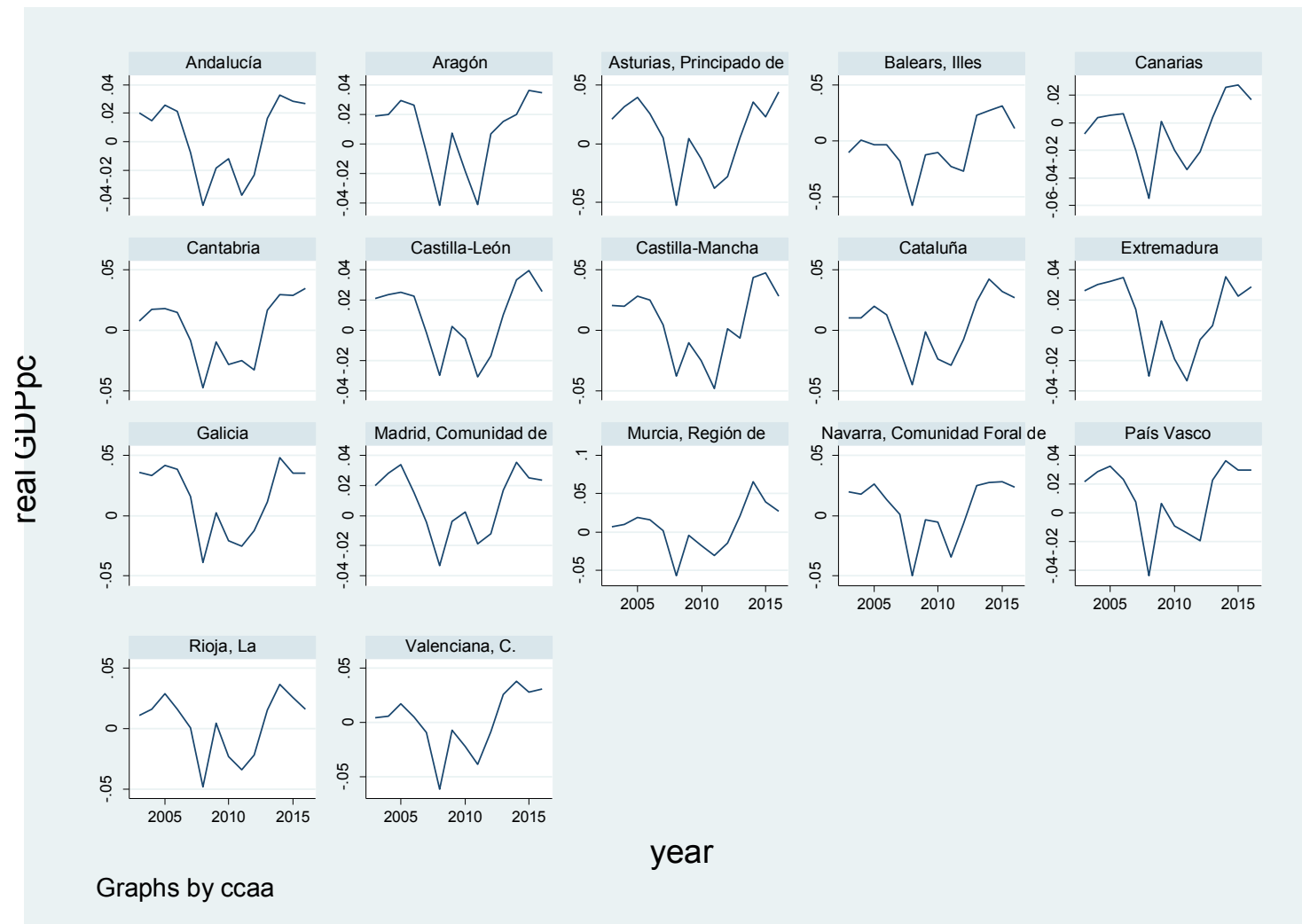

\section{Results}

\section{IV.1 Descriptive Results}

Just for descriptive purposes, Figure 1 shows the relationship between regional growth rates and redistribution. "Rich regions" are those in which the variable redistribution takes a value below one (in the $x$-axis) at least one year during the period 2002-2016, and the "poor" ones present redistribution values above 1. Only 6 regions are considered as "rich" following our definition: Baleares (6), Castilla la Mancha (1), Cataluña (1), Madrid (6), Navarra (3) and Valencia (2). We provide the number of years that exhibit a value below 1 (in brackets). 
Figure 2 Redistribution and regional growth

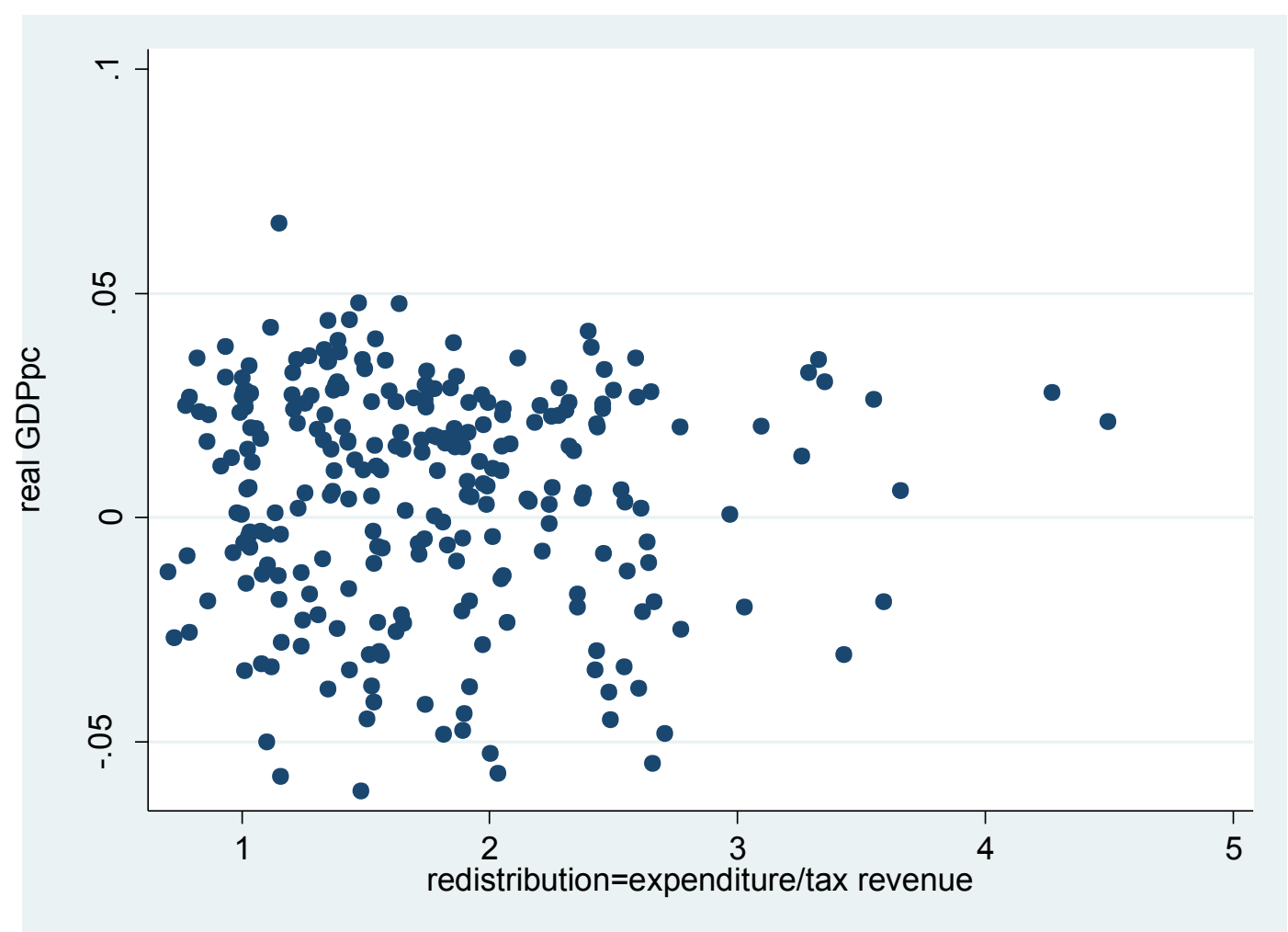

At his point, it is very important to stress that data indicates that Basque Country and Navarra are not rich regions. This might be due to the fact that Basque Country has a special financing regime, for two reasons. First, most taxes are collected by the Basque Government and then transfers some resources to the CG, aimed at financing some its exclusive responsibilities (defense, international affairs, interregional solidarity, etc.). It is widely accepted that the contributions of the Basque Country and Navarra to solidarity is scarce at best. Second, because taxes are not collected by the Regional Basque Government but by their Provinces (Diputaciones Forales being considered local administrations rather than regional ones). In other words, Diputaciones collect all revenues, they keep a part for their own activities and the rest is transferred to those Regional Governments. This means that some fiscal resources are not considered in our analysis because we avoided dealing with 'local' expenditure.

\section{IV.2 Econometrics Results}

The results of our estimates are presented in Table 1, Table 2 and Table 3.

Differences between estimates 1 and 2 are due to the fact that estimates 2 consider a nonlinear specification for the variable Tax Rate.

As mentioned earlier, the best estimation in order to test the relationship in the long run between growth and redistribution is that of the between estimator approach.

First, results in Table 1 (columns 1 and 2), suggest that no relationship is significant considering all regions. However, estimates in columns (3) and (5) indicate that regional redistribution causes a negative effect on regional growth both to rich and poor regions. It is important to remark that we are not considering $\beta$ but $(1-\beta)$ instead. Therefore, a larger ratio expenditure/taxes (1- $\beta$ ), or, alternatively a lower the level of 
redistribution $(\beta)$, causes a positive effect on regional growth. However, the coefficient for the variable redistribution differs across regions and it is much larger in the donor. This result confirms the initial hypothesis that redistribution is harmful for growth, regardless whether the region is a donor or a recipient. This result might be explained by the fact that larger levels of redistribution will provide more resources to the poor region in the short run but they will grow at a reduced path compared to a scenario with lower levels of redistribution.

This result is confirmed for the poor region group (even if we use a nonlinear specification for the variable Tax Rate), and it becomes non-significant now for the rich region.

Concerning the variable that represents the level of education of the working population, results indicate that this variable has a positive impact of GDP growth in the rich regions, while the coefficient is not significant in the poor regions

Table 1 Dependent variable: real GDPpc growth rate (between group estimator)

\begin{tabular}{|l|c|c|c|c|c|c|}
\hline & All1 & All2 & Poor1 & Poor2 & Rich1 & Rich2 \\
\hline & $\mathrm{b} / \mathrm{se}$ & $\mathrm{b} / \mathrm{se}$ & $\mathrm{b} / \mathrm{se}$ & $\mathrm{b} / \mathrm{se}$ & $\mathrm{b} / \mathrm{se}$ & $\mathrm{b} / \mathrm{se}$ \\
\hline & $(1)$ & $(2)$ & $(3)$ & $(4)$ & $(5)$ & $(6)$ \\
\hline Redistribution $(1-\beta)$ & 0.0002 & 0.0003 & $0.0007^{*}$ & $0.0035^{*}$ & $0.0164^{* *}$ & 0.0078 \\
\hline & $(0.0002)$ & $(0.0007)$ & $(0.0004)$ & $(0.0015)$ & $(0.0028)$ & $(0.0013)$ \\
\hline Tax_rate & 0.0166 & 0.1024 & 0.2604 & $3.4027^{*}$ & 0.0215 & $-1.1609^{*}$ \\
\hline & $(0.0577)$ & $(0.5272)$ & $(0.1750)$ & $(1.6499)$ & $(0.0220)$ & $(0.1658)$ \\
\hline Tax rate squared & & -0.3212 & & -17.9732 & & $4.2379^{*}$ \\
\hline & & $(1.9605)$ & & $(9.3981)$ & & $(0.5941)$ \\
\hline Educated share of labour & & & & & & \\
force & -0.0144 & -0.013 & -0.0419 & -0.0091 & $0.1145^{* *}$ & $0.0568^{*}$ \\
\hline & $(0.0264)$ & $(0.0287)$ & $(0.0349)$ & $(0.0343)$ & $(0.0194)$ & $(0.0089)$ \\
\hline Constant & 0.0096 & 0.0039 & 0.0003 & -0.1502 & $-0.0721^{* *}$ & 0.0356 \\
\hline & $(0.0111)$ & $(0.0364)$ & $(0.0219)$ & $(0.0809)$ & $(0.0122)$ & $(0.0153)$ \\
\hline & & & & & & \\
\hline $\mathrm{N}$ & 255 & 255 & 165 & 165 & 90 & 90 \\
\hline Regions & 17 & 17 & 11 & 11 & 6 & 6 \\
\hline Periods (years) & 15 & 15 & 15 & 15 & 15 & 15 \\
\hline Adjusted R & 0.094 & 0.096 & 0.408 & 0.632 & 0.952 & 0.999 \\
\hline
\end{tabular}

In Table 2 we provide fixed effects estimates (we also introduce between groups estimations from the previous table, for comparative purposes).

We observe that none of the estimates provides any significant coefficient. However, we must remind that fixed effects estimates do not allow us to estimate a relationship between two variables in the long run but rather in the short run, which is not what the theoretical model predicts. 
Table 2 Fixed Effects Model vs. between group estimator

\begin{tabular}{|l|c|c|c|c|c|c|}
\hline & All & All_fe & Poor1 & Poor_fe & Rich1 & Rich_fe \\
\hline & $(1)$ & $(7)$ & $(3)$ & $(8)$ & $(5)$ & $(9)$ \\
\hline \hline Redistribution $(1-\beta)$ & 0.0002 & 0.0003 & $0.0007^{*}$ & 0.0002 & $0.0164^{* *}$ & 0.0026 \\
\hline & $(0.0002)$ & $(0.0004)$ & $(0.0004)$ & $(0.0003)$ & $(0.0028)$ & $(0.0057)$ \\
\hline Tax rate & 0.0166 & -0.2171 & 0.2604 & $0.5649 *$ & 0.0215 & -0.2753 \\
\hline Educated share of labour force & $(0.0577)$ & $(0.1635)$ & $(0.1750)$ & $(0.2896)$ & $(0.0220)$ & $(0.4647)$ \\
\hline & $(0.0264)$ & $(0.0513)$ & $(0.0349)$ & $(0.0558)$ & $(0.0194)$ & $(0.1083)$ \\
\hline Constant & 0.0096 & 0.0299 & 0.0003 & -0.0023 & $-0.0721^{* *}$ & 0.0677 \\
\hline & $(0.0111)$ & $(0.0195)$ & $(0.0219)$ & $(0.0219)$ & $(0.0122)$ & $(0.0563)$ \\
\hline \hline $\mathrm{N}$ & 255 & 255 & 165 & 165 & 90 & 90 \\
\hline Regions & 17 & 17 & 11 & 11 & 6 & 6 \\
\hline Periods (years) & 15 & 15 & 15 & 15 & 15 & 15 \\
\hline Adjusted R & 0.094 & 0.055 & 0.408 & 0.084 & 0.952 & 0.038 \\
\hline
\end{tabular}

In these estimates we observe that the variable that represents the level of education of the population is not significant for any of the regions

Finally, in Table 3 we provide the results of between group estimator using an alternative definition for regional redistribution. In particular we use the level of redistribution which is obtained from the Financing Agreements for the Autonomous Communities as commented.

It is important to remark that Baleares and Madrid are the only regions that are donors during the whole period. Nevertheless, according to our data Cataluña was a receiver region from 2002 to 2008 and became a donor region since 2009. So, in other to split the sample into "poor" and "rich" regions we use the median. Those region above the median are considered as "rich" regions and the rest are considered as "poor" regions.

Again, under this specification none of the coefficients of the variables in the estimation are significant. 
Table 3. Dependent variable: real GDPpc growth rate (between group estimators)

\begin{tabular}{|l|c|c|c|}
\hline & All & Poor & Rich \\
\hline & $\mathrm{b} / \mathrm{se}$ & $\mathrm{b} / \mathrm{se}$ & $\mathrm{b} / \mathrm{se}$ \\
\hline $\begin{array}{l}\text { Vertical and } \\
\text { Horizontal } \\
\text { transfers/taxes }\end{array}$ & $(10)$ & $(11)$ & $(12)$ \\
\hline & & & \\
Funds / taxes & 0,0012 & 0,0066 & 0,0041 \\
\hline & $(0.0080)$ & $(0.0229)$ & $(0.0086)$ \\
\hline Tax Rate & $-0,0401$ & 0,4888 & $-0,3033$ \\
\hline & $(0.2455)$ & $(0.8272)$ & $(0.2656)$ \\
\hline $\begin{array}{l}\text { Educated share of } \\
\text { labour force }\end{array}$ & $-0,0118$ & $-0,0142$ & 0,0413 \\
\hline & $(0.0457)$ & $(0.1814)$ & $(0.0555)$ \\
\hline Constant & 0,0116 & $-0,0342$ & 0,0094 \\
\hline & $(0.0374)$ & $(0.1467)$ & $(0.0432)$ \\
\hline & & & \\
\hline $\mathrm{N}$ & 210 & 98 & 98 \\
\hline Regions & 15 & 7 & 7 \\
\hline Periods (years) & 14 & 14 & 14 \\
\hline Adjusted R & 0,037 & 0,399 & 0,56 \\
\hline & & & \\
\hline
\end{tabular}

\section{Conclusions}

Our estimates suggest that regional redistribution has a negative impact on regional GDP growth rates, regardless of whether the region is recipient or donor of fiscal transfers. This suggests that others things equal, redistribution is harmful for growth.

One policy implication of our results is that donor regions do find a solid argument for secession, especially in a framework where Regional Governments, or regional interests, are not represented, say in the Senate which is supposed to be a Chamber of territorial representation.

Further efforts should be devoted to estimate the impact of redistribution on households' welfare. This would provide an accurate estimation of the impact of interregional redistribution. However, we must remark that private consumption is affected by redistribution within the same region and available data does not allow disentangling to which extent consumption is influenced by interregional on intraregional redistribution. 


\section{References.}

Antràs, Pol (2012), "La desagradable aritmética de la independencia: respuesta a la entrada de José Vicente Rodríguez Mora”, Nada es Gratis (fedeablogs), 14-10-21012

Becker, Gary (2012), “Breakup of Countries: No Economic Disaster”, becker-posnerblog.com, 04-12-2012.

Borrell, J, (2015), Las cuentas y los cuentos de la Independencia. Editorial Catarata.

Bosch, Núria (2013), Anàlisi econòmica del procés d'independència de Catalunya, Fundació Josep Irla, Barcelona, 2013.

Buchanan, J. and R. L. Faith (1987), "Secession and the Limits of Taxation: Towards a Theory of Internal Exit". American Economic Review, vol 77/5.

Castells, A. (2014), "Catalonia and Spain at the crossroads: financial and economic aspects". Oxford Review of Economic Policy, Volume 30, Issue 2, 1 July 2014, Pages 277-296

Cuadras, X. and M. Guinjoan (2011), Sense Espanya (Balanç econòmic de la independència), Pòrtic, Barcelona.

Cuadras, X. and T. Rodon (2017), "Catalan secessionism: is it really about the money?", in http://focus.barcelonagse.eu/catalan-secessionism-is-it-about-money/

De la Fuente, A. (2004), "Second-best redistribution through public investment: a characterization, an empirical test and an application to the case of Spain". Regional Science and Urban Economics, 34 (2004) 489-503.

De la Fuente, A. (2008), "Inversión en infraestructuras, crecimiento y convergencia regional". Colección Estudios Económicos 20-08. FEDEA.

Paluzie, E. (2010), "The costs and benefits of staying together: The Catalan case in Spain", in The political Economy of inter-Regional Fiscal Flows, chapter 14 Edward Elgar Publishing.

Petchey, J. (2016), "Equalization and Spatial Location Efficiency: The Example of Australia”. Mimeo. School of Economics and Finance, Curtin University of Technology, Perth, Western Australia

Rodríguez Mora, J.V. (2012), "Portugal, España, Cataluña. Amics per sempre (I and II)", Nada es Gratis (fedeablogs), 12 and 14-10-21012.

Rosselló, J. (2003) "Regional Redistribution and Growth". Investigaciones Económicas, vol XXVII (2) 2003.

Vaillancourt, F. (2010), "The costs and benefits of constitutional options for Québec and Canada". In The Political Economy of Inter-Regional Fiscal Flows, Bosch N. and Espasa M. (Editors), Edward Elgar Publishing.

Vaubel, Robert (2013), "Secession in the European Union" Economic Affairs, Vol. 33, Issue 3, pp. 288-302, 2013. 


\section{Annex 1. Main statistics}

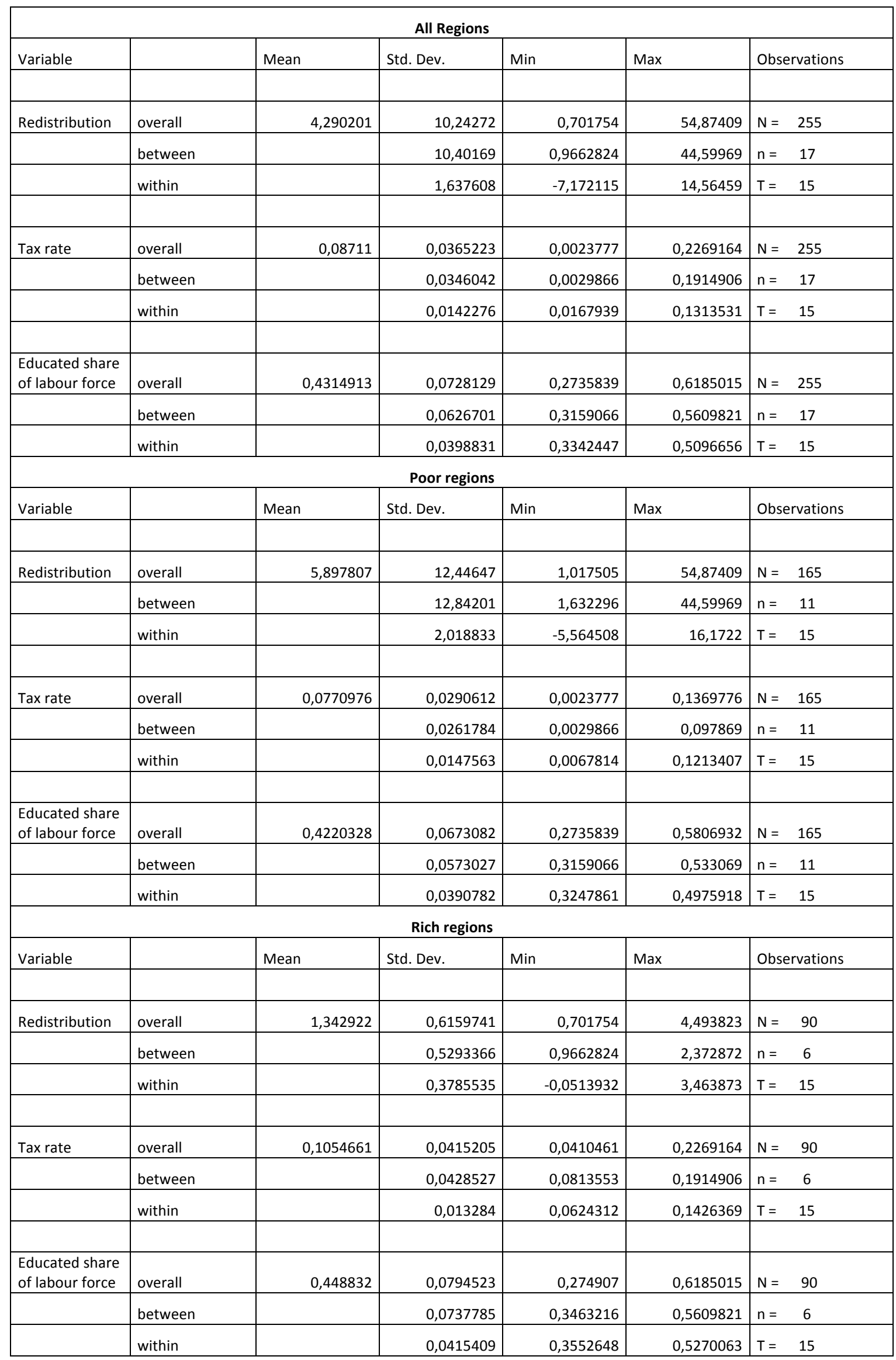




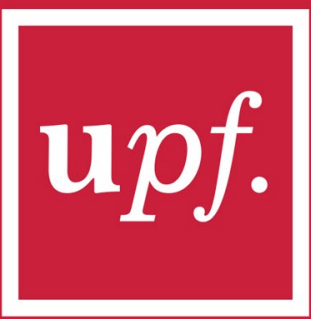

Universitat Pompeu Fabra Barcelona

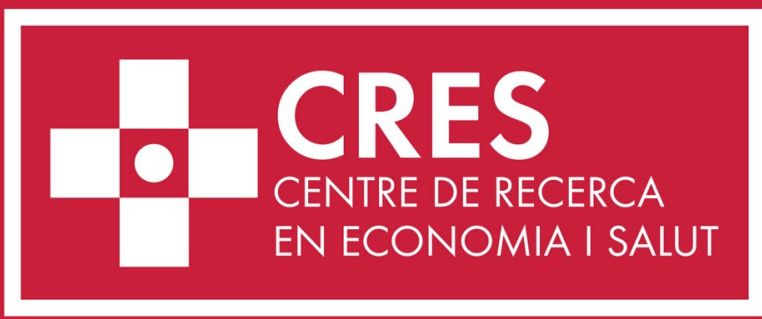

